\title{
Risk management in pathology
}

\section{E L Teare, R G Masterton}

\section{Principles and practice in an era of clinical governance}

$A^{\prime \prime}$ though doctors have been described as natural risk takers, ${ }^{1}$ the assessment approach to their care of patients could more accurately be described as risk management. The broader postgraduate learning of pathologists adds to this clinical approach with topics such as health and safety and occupational health hazards. Despite all this, formal instruction in risk management is absent from the current training programme of the Royal College of Pathologists. This demands attention because in relation to patients and doctors, the risk reduction approach is a fundamental pledge made by the government, the medical profession, and the National Health Service (NHS). ${ }^{2}$ It is also reflected in the new Clinical Pathology Accreditation guidelines, which focus on continual improvement as a central and integral component of laboratory management. These developments have far reaching implications in the context of clinical governance because they ensure that all laboratories have a clear statement of intent with respect to their standard of service. This includes a commitment to good professional practice as recently published by the Royal College of Pathologists. The present contribution will review the principles and practice of risk management as they relate to the environment of pathology.

\section{BACKGROUND}

There is an explicit wish from the public and politicians for clear accountability and deliverability within the NHS. This is to be achieved through the mechanism of performance assessment against defined targets; the tools determining the structure within which pathology will operate being the same as for all other areas of the NHS. These are identified as a clear structure of core processes to guide action and are embodied in corporate governance, which embraces the three interrelated approaches of controls assurance, ${ }^{34}$ clinical governance, ${ }^{5-8}$ and risk management. ${ }^{9}$

Risk management is an iterative process of risk analysis and the taking of appropriate measures to minimise or mitigate the risks that have been identified. With the Clinical Negligence Scheme for Trusts introducing a new standard relating to the control of all hazards and the Commission for Health Improvement also expecting to see infection control as a key component of risk management, trusts need to demonstrate that they have a managed environment that minimises risk, including that of infection, to patients, staff, and visitors. This link between the trust's legal exposure and risk management is explicit in the adoption from April 2002 of a shared approach to standards from the Department of Health's Controls Assurance Team and the NHS Litigation Authority.

"Risk management is an iterative process of risk analysis and the taking of appropriate measures to minimise or mitigate the risks that

have been identified"

Risk management is everyone's business and should be seen as an integral part of everyday work. The benefits to both the organisation and the individual are based on ensuring that the risks to the quality and delivery of patient care are actively minimised or avoided altogether. A related and equally important feature is that this approach allows the reputation and finances of the trust to be protected, along with the people for whom it has responsibility. Indeed, every trust is required to make a formal "statement of internal control" in the annual accounts that they have an ongoing process which identifies the risks to the achievement of its policies, aims, and objectives, evaluates the nature and extent of those risks, and manages them effectively and economically. To do this, every directorate, including pathology, must build up a profile of risk. Each directorate needs to develop a system that works for them.

In support of the delivery of risk management within the NHS, the Department of Health's Controls Assurance Team has published a controls assurance standard on the subject. ${ }^{10}$ This requires that a risk management system is in place to manage risks, hazards, incidents, complaints, and claims. The standard seeks to ensure that all NHS organisations have comprehensive risk management processes in place for managing risk along the lines of "an organisation with a memory". ${ }^{11}$ Trusts are expected to develop and integrate risk management processes, developing a learning culture via a clear objective and leadership from the top. This means that the process needs to work through business planning, each clinical director being appraised on a governance improvement plan for their directorate. Although it is acknowledged that there can be no "one size fits all", because the design of a risk management system depends upon local factors, the standard focuses on the required form and function of risk management, rather than detailed application or precise delivery techniques.

\section{GENERAL ISSUES}

Because the management of risk is directed at eliminating, reducing, and/or effectively controlling all aspects of risk related to the provision of health care services, this pivotal performance target must be embraced by pathology and given at least equal ranking to its other core objectives. As a very minimum, full compliance with all its statutory requirements must be pathology's target in this regard. The most effective and transparent way to demonstrate this commitment is to introduce controls at source whenever any activity, new or old, is being assessed.

To help and support staff in delivering risk management there are several fundamental principles that should be woven through the organisational arrangements. Against a background where the trust has clearly established structures and procedures, pathology departments must create a suitable environment for risk management and should undertake education and training to develop staff to take personal responsibility about making their work and workplace safe. As part of this environment, there should be positive encouragement and support for staff to report errors and near misses, so that learning and improvement can take place. Within pathology, staff must be educated that they have a personal responsibility to perform their duties properly and that they will be accountable for their own decisions and actions. Whereas it is not possible to adopt a complete "no blame" culture, staff should be reassured that they will not be disciplined for errors that are neither wilful nor criminal, and in recognition of this, the department should make nonthreatening arrangements for the meaningful discussion of such incidents arising from human error. Multidisciplinary networking is essential and pathology departments should ensure that such learning is used to improve procedures and processes and, where appropriate, should consider the sharing of such learning points with other departments, both within and without their own organisations. 
Table 1 An example of the features of a model risk register

\begin{tabular}{|c|c|c|c|c|c|}
\hline Risk category & Impact on service & Frequency likelihood & Risk priority & Controls & Residual risk \\
\hline $\begin{array}{l}1 \text { Clinical } \\
2 \text { Financial } \\
3 \text { Operational } \\
4 \text { Strategic } \\
5 \text { Human resources } \\
6 \text { Environmental } \\
7 \text { Reputation }\end{array}$ & $\begin{array}{l}1 \text { Catastrophic } \\
2 \text { Major } \\
3 \text { Moderate } \\
4 \text { Minor } \\
5 \text { Insignificant }\end{array}$ & $\begin{array}{l}1 \text { Almost certain } \\
2 \text { Likely } \\
3 \text { Moderate } \\
4 \text { Unlikely } \\
5 \text { Rare }\end{array}$ & $\begin{array}{l}1 \text { Very high } \\
2 \text { High } \\
3 \text { Significant } \\
4 \text { Moderate } \\
5 \text { Low }\end{array}$ & $\begin{array}{l}1 \text { Management } \\
2 \text { Policies/procedures } \\
3 \text { Contingencies } \\
4 \text { Active controls } \\
5 \text { Passive controls }\end{array}$ & $\begin{array}{l}1 \text { Weak } \\
2 \text { Incomplete } \\
3 \text { Adequate } \\
4 \text { Strong } \\
5 \text { Over controlled }\end{array}$ \\
\hline
\end{tabular}

\section{RISK MANAGEMENT PRACTICE}

An effective risk management system will incorporate the following stages ${ }^{12}$ :

- Identification of risk.

- Analysis of identified risk.

- Control of risk.

- Evaluation of control measures.

In addition to conducting such assessments on all new circumstances, pathology departments should also set up a programme of risk evaluation on a regular, annual basis. There are many methods that can be used, among the most common of which is the creation of a departmental risk register. The fields of a risk register should be decided locally. Table 1 shows an example of possible fields with an approach to assessment criteria. Pathology risk registers should be compatible with the local trust format, but need not be identical as long as the core fields are included. There are many choices for risk treatment, which range from acceptance of the risk to control, avoidance, reduction, and transfer.

"There should be positive
encouragement and support for
staff to report errors and near
misses, so that learning and
improvement can take place"

It is particularly important that pathology departments ensure that appropriate risk management occurs in all areas of their activity and influence. This will vary slightly from one specialty to another and needs to cover not just laboratory practice, but also clinical activity, (for example, in haematology and infection control), in addition to aspects of point of care testing. This means that both primary and secondary care will need to be considered. Multidisciplinary laboratory areas must also be robustly dealt with and integration with the audit process is essential. Furthermore, because organisational and professional boundaries will need to be crossed, evidence and an appreciation of multidisciplinary team working is paramount.

\section{CRITICAL INCIDENTS}

In accordance with the recent expert group report on learning from adverse events in the NHS, there is a requirement for every member of pathology staff to identify and report incidents and near misses. ${ }^{11}$ A subtle and important nuance on this is the recording of situations where things could have been done better, whether from a safety or effectiveness point of view, or merely providing a more economical solution. For every critical incident that occurs, there are invariably hundreds of near misses. Transposition error is a good example for pathology laboratories. Another is the identification of false positive or negative results that occur because of batch failure. Failure to discuss individual incidents in a blame free environment will miss the "bigger" problem. Therefore, it is vital that pathology departments should develop a culture and an environment in which any member of staff can feel "OK" about discussing errors and anomalies. They need to be able openly to challenge conventional ideas and "the way it has always been done".

Thus, it can be seen that the pathology laboratory needs to become a "learning organisation" within the context of an open and blame free environment. There needs to be a regular opportunity for staff to get together to discuss incidents, near misses, and what is being done in the department to avoid repetition. The clear goal is that by the identification and discussion of such events, organisational learning will occur to prevent them from happening again. To be effective, such an ethos needs to be developed over time, and it also needs to be well documented and thoroughly communicated throughout laboratories to ensure that this learning culture is disseminated and embraced by every individual.

Invariably, when things go wrong, it is because of systems failing rather than individuals. There needs to be an understanding therefore that improvement is usually around systems, although individual training and development may be identified as a quality improvement issue. Therefore, lying behind this must be effective evidence based systems. These need to include the audit process itself, in addition to education, training, research, and development. It is essential that none of these happen in isolation and all must be integrated together into the laboratory's governance system, with the involvement of all staff, whoever they are.

The classification of critical incidents is still in its infancy and it is likely that the approach to such assessments in laboratories will be different from the clinical situation. ${ }^{13}$ It would be extremely helpful if a central agency would undertake the construction of the main groups and subgroups of pathology, clinical, and laboratory incident assessments because without an agreed and standard approach, comparisons and consistency will not be possible. In this context it could be envisaged that, in the future, benchmarking between laboratories could form part of a performance assessment approach. Scoring systems adopting a matrix approach based on the severity plus the nature of the episode are already being developed in clinical practice, $^{14}$ and their extension into pathology could be easily achieved.

\section{CONCLUSIONS}

The final essential part of risk management in pathology is to ensure that once a departmental profiling exercise is complete, both it and its attendant action plan are built into the directorate business plan. Where risks are thought to be unacceptable or uncontrollable it is vital that these are brought to the attention of senior trust management at the earliest opportunity. This must include risks across directorate boundaries.

Pathology departments are required to demonstrate that they learn from individual incidents, from aggregate reviews, and from wider experiences. They must show that this learning translates into improvement strategies that are implemented and monitored to ensure sustained quality gains.

\section{"In the future, benchmarking between laboratories could form part of a performance assessment approach"}

At the heart of achieving the above is the need to gain clinical leadership and ownership of the process, while ensuring that everybody has the tools to do the job. The trust must create a clear culture of personal responsibility and accountability among its staff in terms of their roles 
in risk management. Clinical directors and heads of laboratory/service should be managerially appraised with respect to their risk management commitments, and they should be expected to demonstrate improvements year on year. In turn, the key to effective risk management in this setting must be to embed it in the centre of the organisation's culture by gaining understanding, ownership, and education. Central to all this is the leadership of pathologists, self assessment, and audit within the context of a blame free learning organisation.

J Clin Pathol 2003;56:161-163

\section{Authors' affiliations}

E L Teare, Chelmsford Public Health

Laboratory, New Writtle Street, Chelmsford CM2 OYX, UK

R G Masterton, Ayrshire and Arran Acute

Hospitals Trust, Crosshouse Hospital,

Crosshouse, Kilmarnock, Ayrshire KÁ2 OBE, UK
Correspondence to: Dr E L Teare, Chelmsford Public Health Laboratory, New Writtle Street, Chelmsford CM2 OYX, UK; Iteare@phls.org.uk

\section{REFERENCES}

1 Masterton R, Teare L, Richards J. Hospital Infection Society/Association of Medical Microbiologists. Towards a Consensus II. Workshop I. Hospital-acquired infection and risk management. J Hosp Infect 2002;51:17-20.

2 Department of Health. A quest for excellence. London: The Stationary Office, 2000

3 NHS Executive. Governance in the new NHS: controls assurance statements 1999/2000: risk management and organisational controls. Health Service Circular HSC 1999/123. London: Department of Health, 1999.

4 NHS Executive. Controls assurance standard-infection control. London: Department of Health, 2001.

5 NHS Executive. Clinical Governance: in the new NHS. Health Service Circular HSC 1999/065. London: Department of Health, 1999

6 NHS Executive. Department of Health. A first class service: quality in the new NHS. Health
Service Circular HSC 1999/033. London: Department of Health 1999.

7 Department of Health. A first class service: quality in the new NHS. London: Department of Health, 1998.

8 Masterton RG, Teare EL. Clinical governance and infection control in the United Kingdom. J Hosp Infect 2001:47:25-31.

9 Farrington M, Pascoe G. Risk management and infection control-time to get our priorities right in the United Kingdom. J Hosp Infect 2001;47:19-24.

10 NHS Executive. Controls assurance standard-risk management. London: Department of Health, 2001.

11 Department of Health. An organisation with a memory. Report of an expert group on learning from adverse events in the NHS, chaired by the Chief Medical Officer. London: The Stationery Office, 2000.

12 Wilson J. Risk reviews and using risk management strategy. In: Wilson J, Tingle J, eds. Clinical risk modification. Oxford: Butterworth-Heinemann, 1999:39-64.

13 Mcllwain J. Reported clinical incidents: a natural classification of main groups and subgroups. Clinician in Management 2001;10:147-52.

14 Mcllwain J. A conceptual approach for the rapid reporting of clinical incidents: a proposal for benchmarking. Clinician in Management 2001;10:153-60.

New JCP online submission and review system

We are pleased to inform authors and reviewers of the new online submission and review system at JCP. Developed by HighWire Press (CA, USA), Bench Press is a fully integrated electronic system that utilises the web to allow rapid and efficient submission of manuscripts. It also allows the peer review process to be conducted entirely online. We are one of the first journals in the BM Special Journals group to go online in this way. The aim, apart from saving trees, is to speed up the often frustratingly slow process (for both authors and editors) from submission to publication. Many reviewers might appreciate this too. Authors may submit their manuscript in any standard word processing software. Acceptable standard graphic formats include: jpeg, tiff, gif, and eps. The text and graphic files are automatically converted to PDF for ease of distribution and reviewing purposes. Authors are asked to approve their submission before it formally enters the reviewing process. On approval by the authors, the submission is passed to the editor and/or reviewers via the web. All transactions are secure.

To access the system click on "SUBMIT YOUR MANUSCRIPT HERE" on the JCP homepage: HYPERLINK http://www.jclinpath.com, or you can access Bench Press directly at HYPERLINK http://submit-jcp.bmijournals.com.

We are very excited with this new development and would encourage authors and reviewers to use the online system whenever possible. As editors, we will use it all the time, the up side being lack of need to travel to the editorial office to deal with papers, the down side having no more excuses to postpone decisions on papers because we are "at a meeting"!

The system is very easy to use and should be a big improvement on the current peer review process. Full instructions can be found on Bench Press http://submit-jcp.bmijournals.com and JCP online at http://www.jclinpath.com. Please contact Natalie Davies, Project Manager, HYPERLINK mailto:ndavies@bmigroup.com for any further information. 